\title{
A short commentary on substituted Indoles, pyrazolones and imidazolinones
}

\author{
Mohammad Asif ${ }^{1, *}$, Mrityujoy Acharya ${ }^{2}$ \\ ${ }^{\mathbf{1}}$ Associate Professor, ${ }^{\mathbf{2}}$ Assistant Professor, ${ }^{1}$ Dept. of Pharmacy, ${ }^{\mathbf{1}}$ Guru Ram Das (PG) Institute of Management and Technology, Dehradun, \\ Uttarakhand, Gopiballavpur, Multisuper Speciality Hospital, Gopiballavpur, Jhargram, West Bengal, India

\section{*Corresponding Author: Mohammad Asif} \\ Email: aasif321@gmail.com
}

\section{Introduction}

German scientist Hugo Schiff discovered compounds which have azomethine group. Various azomethines were prepared for different of amines and aldehydes and used for diverse industrial applications. ${ }^{1-3}$ Schif's bases were also used for their industrial applications such as metal chelating ability and analytical purpose for various metal ions testing. ${ }^{4}$ They were used as intermediates for the synthesis of various biological active heterocycles compounds like $\beta$-lactums and thiazolidinones. The mechanism of action of some antibiotics such as streptomycin, tetracycline, aspergillic acid and usinic acid were exhibited antibacterial effect due to their metal chelating activities. ${ }^{5,6}$ Metal chelating abilities of Schif's bases, inspired several chemist to test the antibacterial and other biological activities of Schif's bases. This was a distraction from research on diazo compounds, as diazo compounds were proved to be toxic and azomethines were believed as substitute to diazo compounds in search for novel molecules and resulted in synthesis of various Schif's bases for testing their biological activities. Some amino acid-schiff bases 1, 2 were tested for their antibacterial activity against various gram positive and gram negative bacterial strains and some of the tested Schiff's bases exhibited promising activity. ${ }^{7}$ A series of Schif's bases 3 which have isatin nucleus and exhibited moderate pharmacological activities such as analgesic, antiinflammatory, and anti-pyretic activities. All the tested compounds. $^{8}$

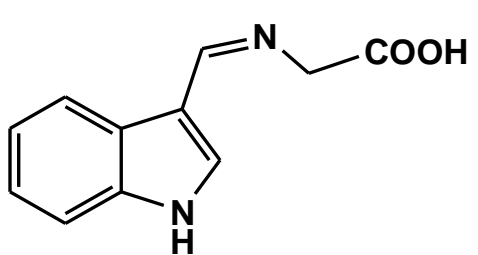

1<smiles>N=Cc1c[nH]c2ccccc12</smiles>

2<smiles>[R]N=C1C(=O)N([R7])c2ccccc21</smiles>

$3 \mathrm{R}=$ substituted phenyl $\mathrm{R}^{\prime}=$ alkyl, substituted alkyl

Substituted Pyrazolinones: Some Schiff bases of macrocyclic-2,6-bis (2- and 4-formylaryloxy-methyl) pyridines were exhibited anti-cancer activity against cancer cells of breast, colon, non-small cell lung, ovarian and renal cancers. ${ }^{9}$ A number of azomethines were possess significant antibacterial, anti-mycobacterial, antiviral, antifungal, anticancer, analgesic, anti-inflammatory, antioxidant, anthelmintic, and diuretic activities. ${ }^{10-12}$ Pyrazole and its derivatives are important nitrogen containing heterocyclic compounds having extensive spectrum of biological activities. Some of the useful drugs like Celecoxib (COX-2 inhibitor), Oxypheynylbutazone, Phenylbutylzone, Phenazone (NSAID) and Sulphinpyrazone (uricosuric agent) contain pyrazole as basic skeleton.<smiles>CC1=NN(c2ccc(S(N)(=O)=O)cc2)C(c2ccccc2)C1</smiles>

Celecoxib (COX-2 Inhibitor)<smiles>CCCCC1C(=O)N(c2ccccc2)N(c2ccccc2)C1=O</smiles>

Phenylbutazone (NSAID)<smiles>CCCCC1C(=O)N(c2ccccc2)N(c2ccc(O)cc2)C1=O</smiles>

Oxyphenylbutazone (NSAID) 


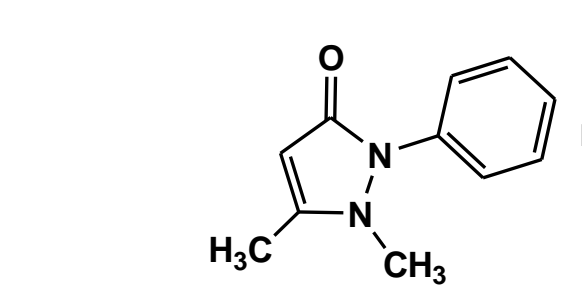

Phenazone (NSAID)

Various substituted pyrazoline 4 were exhibited analgesic activity $^{13}$ and pyrazolone 5 were exhibited analgesic, ulcerogenic and antioxidant activities. Few<smiles>O=C1C(CCCOc2ccccc2)C(=O)N(c2ccccc2)N1c1ccccc1</smiles>

Sulphinpyrazone (Uricosuric agent) compounds were exhibited analgesic activity equal to Diclofenac sodium. ${ }^{14}$ Some pyrazolone derivatives were exhibited the antifungal activity $6 .{ }^{15}$

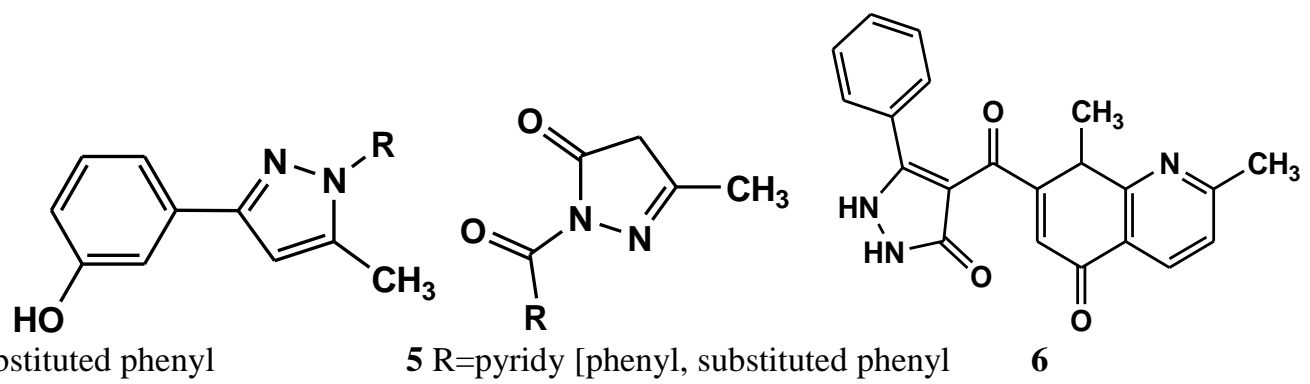

$4 \mathrm{R}=$ phenyl, substituted phenyl

5 R=pyridy [phenyl, substituted pheny

Pyrazolone derivatives are also possess antitubercular, anti-cancer, anti-HIV, anthelmintic and CNS activities. ${ }^{16-19}$ The azo functionality, pyrazolone derivatives are important pharmacophoric functionalities which are present in various compounds which possess wide range of biological activities. Significance of benzofuran as a biopotent moiety, hence, an attempt to synthesize compounds which contain benzofuran moiety, azo functionality and pyrazolone ring system.

Compounds which contain all the three pharmacophoric groups, i.e. azo functionality, pyrazolone moiety and benzofuran nucleus. ${ }^{20}$ Aromatic primary amine group<smiles>CC1=NN(C(=O)c2cc3ccccc3o2)C(=O)C1=N</smiles><smiles>NNc1ccccc1</smiles>

7a-g

Substituted Imidazolinones: Various compounds containing imidazole ring were used for various disorders having compounds like various anilines were first diazotized, and then treated with compounds which contain active methylene group like ethyl acetoacetate, which form the hydrazono compounds. The hydrazono compounds were refluxed with $\mathrm{NH}-\mathrm{NH}_{2}$ group containing compounds resulting in formation of compounds which contain azo group, pyrazolone moiety and the substituent which is attached to $\mathrm{NH}-\mathrm{NH}_{2}$ group. Some of the (4)-1-(1benzofuran-2-ylcarbonyl)-3-methyl-1-N-pyrazole-4,5dione-4-[(aryl) hydrazones 7a-g exhibited antibacterial and antifungal activities.

$$
\begin{aligned}
7 \mathrm{a} \mathrm{R} & =\mathrm{H} \\
7 \mathrm{~b} \mathrm{R} & =2-\mathrm{C} 1 \\
7 \mathrm{c} \mathrm{R} & =4-\mathrm{C} 1 \\
7 \mathrm{~d} \mathrm{R} & =4-\mathrm{CH}_{3} \\
7 \mathrm{e} \mathrm{R} & =3-\mathrm{C} 1-4-\mathrm{F} \\
7 \mathrm{f} \mathrm{R} & =4-\mathrm{NO}_{2} \\
7 \mathrm{~g} \mathrm{R} & =4-\mathrm{OCH}_{3}
\end{aligned}
$$

such as hypertension, hypersecrtion of gastric acid (antiulcer agents), fungal infections and cancer.<smiles>Clc1cccc(Cl)c1NC1=NCCN1</smiles>

Clonidine (anti-hypertensive)<smiles>Cc1ccc(N(CC2=NCCN2)c2cccc(O)c2)cc1</smiles>

Plientolamine (anti-hypertensive)<smiles>CNC(=S)NCCCc1c[nH]cn1</smiles>

(anti-hypersecretory)<smiles>Cc1cnc([N+](=O)[O-])n1CCO</smiles>

Metronidazole (antiprotozoal) 
Imidazolones have also been found to be linked with various biological activities such as potassium channel opener, phosphodiesterase III/IV inhibition and crop protection $^{21-24}$ activities. Hence, this class of compounds has become a synthetic target for organic and medicinal chemists. Novel imidazolines 8 which are coupled with benzoxazole ring and tested them for anti-histaminic activity. ${ }^{25}$ Compounds 9 which contain imidazolines ring

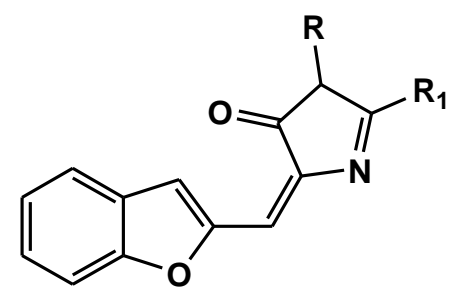

$8 \mathrm{R}=\mathrm{R}=$ pyridyl, pheny, substituted phenyl<smiles>[R]C=C1N=C(c2ccccc2)N(n2cnc3ccc([R])cc3c2=O)C1=O</smiles>

$\mathrm{R}=$ phenyl, substituted phenyl $\mathrm{R}_{1}=$ coupled with quinazolone ring system and tested their antimicrobial activity. Some of the tested compounds exhibited activity comparable to that of standard drugs used, Ciproflaxacin. ${ }^{26}$ Imidazolines moiety and compounds 10 was tested for their anti-tubercular and anticancer activities. Some of the tested compounds were found to active against lung, breast and brain cancer cell lines. ${ }^{27}$

$$
\mathrm{CI}, \mathrm{NO}_{2}
$$

Imidazolone ring system have wide range of therapeutic activities like anticonvulsant, sedative, hypnotic, fungicidal, anti-inflammatory, mono amino oxidase (MAO) inhibitory, anti-aarkinson's and antihypertensive ${ }^{28}$ activities. Inspite of therapeutic impact of imidazolinone ring system, there are hardly only some reports on biological evaluation of compounds which contain both benzofuran and imidazolinone moiety. This inspired to take up the synthesis of novel compounds which contain both benzofuran and imidazolinone ring system and evaluate their biological profile.

Many synthetic strategies have used for synthesis of compounds in which imidazole ring is formed or imidazolinone ring is coupled with other heterocycles, like alteration of esters using aluminum reagents, the reaction between $\mathrm{N}$-ethoxy carbonylthiamides with 1,2-diamines and the reaction of aldehydes with 1,2-diamines followed by $\mathrm{N}$ halosuccinimides. ${ }^{29-31}$ Numerous methods have developed

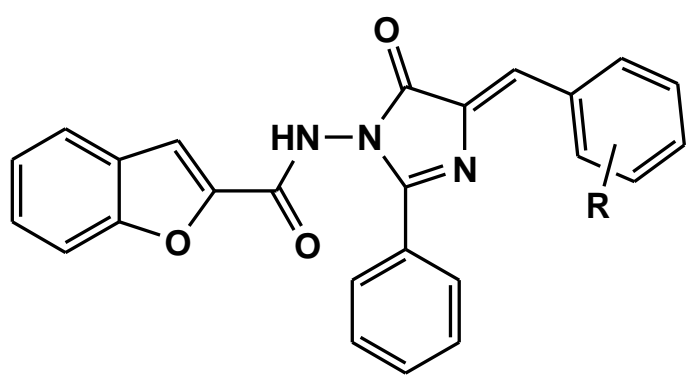

11a-g

\section{References}

1. www.wikepedia.com/hugoschiff

2. S.N. Pandeya, D. Sriram and G. Nath, Arzneim-Forsch 2000;50:55.

3. S.N. Pandeya, D. Sriram and G. Nath, Eur J Med Chem 2000;35:249. where 2-aryl-1,1-dibromoethanes, azalactones, nitriles were used as initial materials. However, various synthetic methods reported so far suffer from difficulties like need anhydrous conditions, harsh reaction situation, prolonged reaction time etc. Hence, attempts are made to find a simple reaction process for forming imidazolinones. In this method amino acid is acetylated or benzoylated using suitable acetylating or benzoylating agent, followed by reaction with aldehydes in acetic anhydride which form 4-arylalkylidene2-phenyl-5-oxazolinones. ${ }^{32}$ These phenyl-5-oxazolinones can be easily converted to imidazolinones by reaction with compounds which contain free $\mathrm{NH}_{2}$ group like amines, hydrazines or carbohydrazides. ${ }^{33}$ The method relating the use of amino acids for the preparation of imidazolinones is a simple and gives good yields. Hence, similar approach is used for synthesis of benzofuran substituted imidazolinones. Some of the N-[(4)-substituted benzylidene-5-oxo-2-phenyl4,5-dihydrolN-imidazol-1-yl]-1-benzofuran-2-carboxamides $11 \mathrm{a}-\mathrm{g}$ have antibacterial and antifungal activities.

11a $\mathrm{R}=\mathrm{H}$

$11 \mathrm{~b} \mathrm{R}=2-\mathrm{Cl}$

$11 \mathrm{cR}=4-\mathrm{C} 1$

$11 \mathrm{~d} \mathrm{R}=4-\mathrm{OCH}_{3}$

$11 \mathrm{e} \mathrm{R}=2-\mathrm{OH}$

$11 \mathrm{f} \mathrm{R}=4-\mathrm{CH}_{3}$

$11 \mathrm{~g} \mathrm{R}=4-\mathrm{N}\left(\mathrm{CH}_{3}\right)_{2}$ 
9. V.P. Lozitsky, G.L. Kamalov, R.N. Lozitskaya, A.I. Zheltvay, A.S. Fedtchouk and D.N. Kryzhanovsky, Acta Bioche Polanica., 2000;47,867.

10. T.L. Hullar and D.L. Failla, J Med Chem 1969;12:420.

11. B.C. Ma, X. Ma, L.R. Yan and D. Yang, Xingyong-Huaxue., 2004, 21, 841.

12. M.G. Thomas, C. Lawson, N. Allanson, B. Leslie, J.R Bottomley, A. McBride and O.A. Olusanya, Bioorg Med. Chem. Lett., 2003, \3, AlZ.

13. K.N. Wadodkar, S.A. Wadhal and P.S. Pandey, Indian J Heterocycl Chem 2004;14:55.

14. M Amir and S Kumar, Indian J. Chem., 2005,44, 2532.

15. Mazhar Kidwai and Richa Sharma, Indian J Chem 2002;41:427.

16. P. Jimonet, A. Francois, M. Barreau and A. Boirean., J Med Chem 199;42:2828.

17. U. Huseyin, K. Vanderpooten and J.P. Stables, J Med Chem 1998;41:1138.

18. N. Ranee, S. Hamilton, A. Luttick, G.Y. Kappner and D.B. Mcconnel, Bioorg Med Chem Lett 2003;13:657.

19. J.H. Hanke and B.A. Pollock, Inflammation Res 199S;44:357.

20. H.H. Parekh, P.P. Patel, A.M. Joshi and K.V. Ketan, Ore J Chem 2003;19:435.

21. F. Cafieri, E. Fattorusso, A. Mangoni and O. TaglialatelaScafati, Tetrahedron Lett 2006;37:3587.

22. M. Los, Pestic. Sci. Biotechnol, Proc. Int. Congr. Pestic. Chem., $6^{\text {th }}$ ed.1987, R. Greenhalgh and T.R.Eds. Roberts, Blachvell: Oxford, U.K,35.

23. G.W. Chan, S. Mong, M.E. Hemling, A.J. Freyer, P.H. Offen, C.W. De Brosse, H.M. Sarau and J.W. Westley, J Nat Prod 1993;56:116.
24. H.L. Yale and J.J. Piala, J. Med Chem., 1966,9, 42.

25. V. Malla Reddy and G.V.S.Rama Sharma, Indian J Heterocycl Chem 1997;7:21.

26. S Rajpurohit, S.P. Garg and P Sah, Indian J. Heterocycl. Chem 2005; 15:129.

27. H.H. Parekh, K.A. Parekh, B.C. Merjs and S.B. Hirpara, Indian J Chem 2003;42:1172.

28. M.D. Shah, N.C. Desai, K.A. Awasthi and A.K. Saxena, Indian J Chem 2001;40:201.

29. G. Nazeef, U. Eder and G. Saute, J Org Chem 1981;46:2824.

30. B. George and E.P. Popadopoulous, J Org Chem 2007;42:441.

31. H. Fujikova, K. Murai and Y. Kita, Tetrahedron Lett, 2005;46:2197.

32. N.C. Sesai, Diptika Dave and G.D. Vyas, Indian J Chem 2000;39:277.

33. M Amir and M Shahroz, Orie J Chem 2008;22:57.

How to cite this article: Asif M, Acharya M. A short commentary on substituted Indoles, pyrazolones and imidazolinones. Int J Pharm Chem Anal 2018;5(4):188191. 